\title{
The Site of Pulmonary Vasomotor Activity during Hypoxia or Serotonin Administration*
}

\author{
Marvin A. Sackner, $†$ Donald H. Will, and Arthur B. DuBois $\ddagger$ \\ (From the Department of Physiology, Graduate Division, University of Pennsylvania, School \\ of Medicine, Philadelphia, $P a$.)
}

Pulmonary arterial pressure increases in dogs exposed to alveolar hypoxia or intravascular infusion of 5-hydroxytryptamine (serotonin). Although most investigators believe that this increase in pressure reflects a vasoconstriction in the pulmonary vascular bed, the site of vasoconstriction, whether venular, capillary, or arteriolar, is controversial. Interpretations have been based previously upon measurements of pressure and flow at various sites in the pulmonary circulation and have been handicapped by the inability to measure the volumes of the segments under study (1-3).

The development of an ether plethysmographic technique to measure pulmonary arterial blood volume in vivo (4) prompted us to reassess the site of vasoconstriction produced by hypoxia or serotonin. To accomplish this, we used cardiac catheters to measure pulmonary arterial and left atrial pressures, dye dilution curves to measure pulmonary blood volume and cardiac output, and the ether plethysmographic method to calculate pulmonary arterial blood volume. These parameters were measured in dogs during 1) a control period, and then during 2 ) respiration of a low concentration of oxygen, or 3) slow intravenous infusion of a solution of 5-hydroxytryptamine. We shall attempt to show that alveolar hypoxia and 5-hydroxytryptamine produced a form of pulmonary vasoconstriction in which there was increased smooth muscle tone of a major portion of the pulmonary arterial tree.

* Submitted for publication June 23, 1965; accepted October 7, 1965.

This work was supported in part by U. S. Public Health Service grants H4797 and H7397.

† American College of Physicians Research Fellow, 1961 to 1964.

Address requests for reprints to Dr. Marvin A. Sackner, Cardiopulmonary Laboratory, Mount Sinai Hospital, 4300 Alton Road, Miami Beach, Fla. 33140.

$\$$ This work was carried out during the term of a Research Career Award of the U. S. Public Health Service.

\section{Methods}

Eleven mongrel dogs weighing 12.3 to $17.7 \mathrm{~kg}$ were used in the experiments. They were anesthetized with sodium pentobarbital in a dosage of $26 \mathrm{mg}$ per $\mathrm{kg}$ body weight. An $8 \mathrm{~F}$ or $9 \mathrm{~F}$ Cournand cardiac catheter ${ }^{1}$ was introduced into the external jugular vein, and under fluoroscopic guidance its tip was placed within the pulmonary artery. A second catheter was placed so that its tip lay within the superior vena cava. A pediatric 7F Brockenbrough left heart catheter ${ }^{1}$ was introduced into the femoral vein and the atrial septum punctured so that the tip of the catheter lay free in the left atrial cavity. The femoral artery was cannulated with polyethylene tubing $25 \mathrm{~cm}$ in length and $2 \mathrm{~mm}$ in diameter in such a way that its tip lay in the distal aorta. The animal was enclosed within a horizontal Plexiglas body plethysmograph (4), then paralyzed with succinylcholine and ventilated with a Starling pump. Intravascular pressures were measured by strain gauges 2 balanced to a reference pressure level $9.8 \mathrm{~cm}$ above the surface of the dog board. Plethysmographic pressure was measured by a differential strain gauge. $^{3}$ A direct-writing instrument ${ }^{4}$ recorded pressures from the strain gauges, the electrocardiogram, and dye concentration from a cuvette densitometer. ${ }^{5}$

The plethysmograph was calibrated by injection and withdrawal of $10 \mathrm{ml}$ of air with a syringe, and this produced a deflection of 20 to $30 \mathrm{~mm}$ on the record. The pulmonary arterial pressure was monitored while the catheter was pulled back slowly until a ventricular pressure tracing was recorded, and then the tip of the catheter was advanced to the point where a pulmonary arterial pressure tracing was again recorded from a position just beyond the pulmonic valve. A $0.5-\mathrm{ml}$ volume of solution, containing $0.1 \mathrm{ml}$ of ether in $0.4 \mathrm{ml}$ of alcohol, was instilled into the catheter to be flushed into the animal by $5 \mathrm{ml}$ of saline. In several experiments designed to determine whether $\mathrm{CO}_{2}$ evolution rate was affected, $0.5 \mathrm{ml}$ of a $0.5 \mathrm{M}$ lactic acid solution was instilled into the catheter to be flushed into the animal by $5 \mathrm{ml}$ of saline, or $5 \mathrm{ml}$ of a $0.9 \mathrm{M}$ sodium bicarbonate solution was placed into the catheter and connecting tubing, and this was also ad-

1 United States Catheter Corp., Glens Falls, N. Y.

2 Model P23D, Statham Transducers, Hato Rey, Puerto Rico.

3 Statham model PM97TC \pm 0.05 to $350 \pm 0.05$ PSID.

4 Polygraph 5, Grass Instrument, Quincy, Mass.

5 Model XP25OA, Waters Corp., Rochester, Minn. 
ministered. After placing the solution in the tubing, the respiratory pump was stopped, its tubes occluded by solenoid valves, ${ }^{6}$ and the solution flushed in by using hand pressure on the syringe barrel to produce rapid injection. As the ether solution is flushed in by the saline, there is an initial rise in plethysmographic pressure, calibrated in terms of volume, as the volume is increased by the $5 \mathrm{ml}$ of saline. After this initial rise in plethysmographic pressure, a slower rise occurs as ether passes from the dissolved state in the pulmonary capillary blood to a gaseous state in the alveoli. The injection of ether at the root of the pulmonary artery allows the determination of a median transit time from this site to the beginning of the pulmonary capillaries. The median transit time is the time between the midvolume point of the injection and the midvolume point of ether evolution and represents the time for half the ether to arrive at the site of gas exchange. Pulmonary arterial blood volume is calculated by multiplying the median pulmonary arterial transit time in seconds by the pulmonary blood flow in milliliters per second.

Dye dilution curves were obtained either before or after the plethysmographic records by injecting in duplicate $1.25 \mathrm{mg}$ of indocyanine green ${ }^{7}$ into the pulmonary artery or left atrium in random order while sampling blood from the distal aorta through a cuvette densitometer ${ }^{5}$ at a withdrawal rate of $24.7 \mathrm{ml}$ per minute. 8 Timeconcentration curves of the downstroke of the dye dilution curves were plotted on a semilogarithmic graph paper, and recirculation was detected and excluded from the calculation by utilizing the linear portion projected downward through two logarithmic cycles. Cardiac output and mean transit times were calculated by the usual StewartHamilton formulas (5). The difference between the mean transit times from the pulmonary artery to the distal aorta and from the left atrium to the distal aorta gave the pulmonary mean transit time. The product of the pulmonary blood flow and the pulmonary mean transit time gave the pulmonary blood volume. The product of the pulmonary blood flow and the median transit time for ether gave the pulmonary arterial blood volume (4). Pulmonary vascular resistance was calculated as the difference in mean pressures in millimeters $\mathrm{Hg}$ between the pulmonary artery and left atrium divided by the pulmonary blood flow in liters per minute.

In every pair of ether and lactic acid or sodium bicarbonate injections, the time taken for half the gas to appear after ether injection was subtracted from the time taken for half the gas to evolve from sodium bicarbonate or lactic acid injections. This yielded a value for the time taken by reactions leading to $\mathrm{CO}_{2}$ liberation to reach half completion and was termed reaction half-time (6).

Arterial blood was obtained for analysis of oxygen

6 8210A95 and 8210A35, Automatic Switch Co., Florham Park, N. J.

7 Cardiogreen, Hynson, Westcott and Dunning, Baltimore, $\mathrm{Md}$.

8 Infusion/withdrawal pump, model 600-900, Harvard Apparatus, Dover, Mass. tension (7), carbon dioxide tension (8), and $\mathrm{pH}$. In most experiments, oxýgen saturation was calculated from a standard canine oxyhemoglobin dissociation curve (9). In the remaining experiments, oxygen saturation was measured by a cuvette oximeter (10).

After control observations, mixtures of 7 to $11 \%$ oxygen in nitrogen, depending on the hypoxia necessary to cause a rise in pulmonary arterial pressure, were delivered by the Starling pump at a respiratory frequency of 24 per minute. Apparatus dead space was approximately $50 \mathrm{ml}$. Pulmonary arterial pressure was monitored, and after a stable plateau was reached, generally from 15 to 30 minutes after institution of the hypoxia, the preceding measurements were repeated. Control measurements while the dogs were breathing air were then repeated. In two of the eleven dogs subjected to hypoxia, control and hypoxic runs were carried out a second time at 45 - to 60 -minute intervals each from the initial observations.

In six of the eleven dogs, after control observations were made, serotonin creatinine sulfate was infused into the superior vena cava at a constant rate of 80 to $500 \mu \mathrm{g}$ per minute. Observations were repeated from 20 to 30 minutes after instituting the infusion.

The paired $t$ test was used to determine whether the differences between means were statistically significant (11). The level of significance was taken as $\mathrm{p}<0.05$.

\section{Results}

Of the eleven dogs used in the series, eight had normal control levels of pulmonary arterial pressure, but three dogs showed pulmonary hypertension during the entire period. In two of these, this was caused by the dog heart worm Dirofilaria immitus $(12,13)$, and in the other by pneumonitis. However, responses to hypoxia and serotonin were similar to those in the normotensive dogs, and therefore these pulmonary hypertensive dogs are included in the statistical analysis of the vasomotor responses to these agents.

Hypoxia. Hypoxia always produced a rise in pulmonary arterial pressures, but pulmonary vascular resistance showed two different responses (Table I). Either there was an increase in pulmonary vascular resistance with no change in pulmonary blood flow, or there was a marked increase in pulmonary blood flow accompanied by a fall in pulmonary vascular resistance. The oxygen saturation during hypoxia in the group with an increase in pulmonary vascular resistance averaged $56 \%$ and in the group with a decrease in pulmonary vascular resistance $49 \%(p>0.05)$.

In eight dogs, pulmonary vascular resistance increased during hypoxia, and this response was ob- 
Effects of hypoxia on

\begin{tabular}{|c|c|c|c|c|c|c|c|c|c|c|c|c|c|c|}
\hline \multirow[t]{2}{*}{$\begin{array}{c}\text { Experi- } \\
\text { ment } \\
\text { no. }\end{array}$} & \multirow[t]{2}{*}{ Dog } & Weight & \multicolumn{2}{|c|}{$\begin{array}{l}\text { Mean pulmonary } \\
\text { arterial pressuret }\end{array}$} & \multicolumn{2}{|c|}{$\begin{array}{c}\text { Mean left } \\
\text { atrial pressure }\end{array}$} & \multicolumn{2}{|c|}{$\begin{array}{l}\text { Pulmonary } \\
\text { blood flow }\end{array}$} & \multicolumn{2}{|c|}{$\begin{array}{l}\text { Pulmonary vas- } \\
\text { cular resistance }\end{array}$} & $\begin{array}{l}\text { Puln } \\
\text { blood }\end{array}$ & $\begin{array}{l}\text { nary } \\
\text { lume }\end{array}$ & \multicolumn{2}{|c|}{$\begin{array}{l}\text { Pulmonary } \\
\text { arterial } \\
\text { blood } \\
\text { volume }\end{array}$} \\
\hline & & $\mathrm{kg}$ & \multicolumn{2}{|c|}{$m m \mathrm{Hg}$} & \multicolumn{2}{|c|}{$m m H g$} & \multicolumn{2}{|c|}{$L / \min$} & \multicolumn{2}{|c|}{$m m H g / L / m i n$} & \multicolumn{2}{|c|}{$m l$} & \multicolumn{2}{|c|}{$m l$} \\
\hline & & & & & & & & & & & & \multicolumn{3}{|c|}{ Increase of pulmonar } \\
\hline 1 & 1 & 12.3 & 11 & 19 & 9 & 7 & 1.61 & 1.53 & & $\ddagger$ & & & 26 & 20 \\
\hline 2 & 2 & 14.1 & 13.5 & 22 & 6 & 7.5 & 2.54 & 2.40 & 1.77 & 6.25 & 100 & 105 & 35 & 16 \\
\hline 3 & 3 & 17.3 & 12 & 23.5 & 10 & 17 & 1.38 & 2.08 & 4.35 & 7.69 & 103 & 100 & 28 & 11 \\
\hline 4 & 3 & 17.3 & 18.5 & 31 & 6.5 & 13 & 1.58 & 1.78 & 5.38 & 7.86 & 128 & 120 & 28 & 21 \\
\hline 5 & 5 & 13.6 & 13.5 & 27 & 6.5 & 4.5 & 1.36 & 1.50 & 5.15 & 9.33 & 75 & 88 & 19 & 18 \\
\hline 6 & 6 & 15.0 & 22.5 & 29.5 & 3.5 & 4.5 & 3.10 & 2.31 & 5.16 & 10.82 & 137 & 159 & 39 & 34 \\
\hline 7 & 7 & 17.7 & 14 & 27.5 & 4 & 6 & 2.01 & 2.55 & 5.22 & 9.01 & 138 & 153 & 32 & 32 \\
\hline 8 & 9 & 12.7 & 39 & 66 & 5 & 5 & 1.04 & 1.35 & 33.65 & 44.44 & 127 & 130 & 33 & 30 \\
\hline 9 & 11 & 15.4 & 10.5 & 17 & 6.3 & 8.1 & 1.76 & 2.68 & 3.12 & 4.47 & 139 & 169 & 29 & 26 \\
\hline Mean & & & 17.1 & 29.2 & 2.1 & 4.2 & 1.82 & 2.02 & 7.98 & 12.48 & 118 & 128 & 30 & 23 \\
\hline $\mathrm{SD}$ & & & 8.0 & 13.7 & \multicolumn{2}{|c|}{$>0.05$} & 0.60 & 0.47 & 9.76 & 12.21 & 24 & 28 & 5 & 8 \\
\hline \multirow[t]{2}{*}{$\mathrm{p}$} & & & \multicolumn{2}{|c|}{$<0.001$} & & & \multicolumn{2}{|c|}{$>0.05$} & \multicolumn{2}{|c|}{$<0.001$} & \multicolumn{2}{|c|}{$>0.05$} & \multicolumn{2}{|c|}{$<0.001$} \\
\hline & & & & & & & & & & & & \multicolumn{3}{|c|}{ Decrease of pulmonar } \\
\hline 1 & 4 & 13.2 & 13 & 28.5 & 6.5 & 10 & 1.12 & 4.15 & 5.80 & 4.45 & 136 & 153 & 14 & 40 \\
\hline 2 & 7 & 17.7 & 15 & 21 & 3 & 3 & 3.20 & 5.00 & 3.75 & 3.60 & 157 & & 35 & 48 \\
\hline 3 & 7 & 17.7 & 17 & 22.5 & 2 & 3 & 2.50 & 3.44 & 6.00 & 5.66 & 152 & 180 & 40 & 54 \\
\hline 4 & 8 & 13.6 & 47 & 61 & 5 & 6 & 1.30 & 2.37 & 32.30 & 23.62 & 180 & 188 & 38 & 44 \\
\hline 5 & 10 & 14.5 & 23 & 34 & 8 & 8.5 & 0.87 & 1.55 & 17.20 & 16.45 & 88 & 88 & 18 & 26 \\
\hline Mean & & & 23.0 & 33.4 & 4.9 & 6.1 & 1.79 & 3.30 & 13.01 & 10.76 & $139 \$$ & 1528 & 29 & 42 \\
\hline $\mathrm{SD}$ & & & 12.4 & 14.5 & 2.2 & 2.8 & 0.91 & 1.23 & 10.74 & 7.92 & 33 & 40 & 11 & 11 \\
\hline $\mathrm{p}$ & & & \multicolumn{2}{|c|}{$<0.01$} & \multicolumn{2}{|c|}{$>0.05$} & \multicolumn{2}{|c|}{$<0.025$} & \multicolumn{2}{|c|}{$>0.05$} & \multicolumn{2}{|c|}{$>0.05$} & \multicolumn{2}{|c|}{$<0.02$} \\
\hline Grand & & & 19.2 & 30.7 & 5.8 & 7.3 & 1.81 & 2.48 & 9.91 & 11.82 & $125 \S$ & $136 \$$ & 30 & 30 \\
\hline SD & & & 10.4 & 14.2 & 2.2 & 3.9 & 0.72 & 1.10 & 10.45 & 10.80 & 28 & 34 & 8 & 12 \\
\hline p & & & & & & 02 & & & & & & .01 & & \\
\hline
\end{tabular}

* Abbreviations: $\mathrm{SaO}_{2}=$ arterial oxygen saturation; $\mathrm{PaO} 2=$ arterial oxygen pressure; $\mathrm{Paco} 2=$ arterial carbon dioxide pressure.

$\dagger$ In these and subsequent calculations in this Table, the left column indicates control values, and the right indicates hypoxia values.
Pulmonary vascular resistance increased if it is assumed that there was no significant change or slight rise of left atrial pressure during hypoxia. \& Paired values (control and hypoxia) used only for statistical calculations.

tained twice in one of the dogs. The mean increase of pulmonary vascular resistance for these eight dogs was $56 \%(\mathrm{p}<0.001)$; pulmonary blood flow and left atrial pressure were not significantly changed, pulmonary arterial pressure increased $12.1 \mathrm{~mm} \mathrm{Hg}(\mathrm{p}<0.001)$, pulmonary arterial blood volume fell from 30 to $23 \mathrm{ml}(\mathrm{p}<$ 0.001 ), and the combined volume of the pulmonary capillaries and veins rose from 88 to $104 \mathrm{ml}(\mathrm{p}<$ $0.005)$. The reaction half-time for bicarbonate timed relative to the ether circulation time did not significantly change during the hypoxia.

In four dogs, pulmonary vascular resistance decreased, and this response was obtained twice in one of the dogs. The mean decrease of pulmonary vascular resistance was $17 \%(\mathrm{p}<0.05)$. Pulmonary blood flow rose from 1.79 to $3.30 \mathrm{~L}$ per minute $(p<0.025)$, pulmonary arterial pressure rose $10.4 \mathrm{~mm} \mathrm{Hg}(\mathrm{p}<0.01)$, left atrial pressure was not significantly changed, pulmonary arterial blood volume rose from 29 to $42 \mathrm{ml}(\mathrm{p}<0.02)$, and the combined pulmonary capillary and venous blood volumes were not altered. The reaction halftimes for lactic acid and sodium bicarbonate showed no particular trend.

The combined results for both groups of dogs during hypoxia showed an increase of $11.5 \mathrm{~mm} \mathrm{Hg}$ in mean pulmonary arterial pressure $(p<0.001)$, an increase of $1.5 \mathrm{~mm} \mathrm{Hg}$ in mean left atrial pressure $(p<0.02)$, and a rise from 1.81 to $2.48 \mathrm{~L}$ per minute in pulmonary blood flow $(\mathrm{p}<0.02)$, Table I. Pulmonary vascular resistance and pulmonary arterial blood volume remained unchanged during hypoxia. There was a slight but significant rise in total pulmonary blood volume and the combined pulmonary capillary and venous blood volumes.

Serotonin. Serotonin administered to five dogs produced an $82 \%$ increase in pulmonary vascular resistance $(p<0.02)$, an increase of $17.5 \mathrm{~mm} \mathrm{Hg}$ in pulmonary arterial pressure $(p<0.005)$, no change in pulmonary blood flow or left atrial pres- 
TABLE I

the pulmonary circulation*

\begin{tabular}{|c|c|c|c|c|c|c|c|c|c|c|c|c|c|}
\hline \multirow{2}{*}{\multicolumn{2}{|c|}{$\begin{array}{l}\text { Pulmonary capil- } \\
\text { lary and venous } \\
\text { blood volume }\end{array}$}} & \multirow{2}{*}{\multicolumn{2}{|c|}{$\mathrm{Sa}_{\mathrm{O} 2}$}} & \multirow{2}{*}{\multicolumn{2}{|c|}{$\mathrm{Pa}_{\mathrm{O} 2}$}} & \multirow{2}{*}{\multicolumn{2}{|c|}{$\mathrm{Pa}_{\mathrm{CO}_{2}}$}} & \multirow{2}{*}{\multicolumn{2}{|c|}{$\mathrm{pH}$}} & \multicolumn{4}{|c|}{ Reaction half-time } \\
\hline & & & & & & & & & & Bica & nate & Lac & cid \\
\hline \multicolumn{2}{|c|}{$m l$} & \multicolumn{2}{|c|}{$\%$} & \multicolumn{2}{|c|}{$m m \mathrm{Hg}$} & \multicolumn{2}{|c|}{$m m \mathrm{Hg}$} & \multicolumn{2}{|c|}{$U$} & \multicolumn{4}{|c|}{ second } \\
\hline \multicolumn{14}{|c|}{ vascular resistance } \\
\hline 65 & 89 & 93 & 37 & 79 & 26 & 38 & 40 & 7.34 & 7.27 & 0.38 & 0.78 & & \\
\hline 75 & 89 & 96 & 50 & 95 & 28 & 27 & 28 & 7.36 & 7.27 & 0.32 & 0.56 & & \\
\hline 100 & 99 & 96 & 61 & & & & & & & 0.12 & 0.44 & & \\
\hline 56 & 70 & 92 & 45 & 76 & 38 & 31 & 27 & 7.28 & 7.16 & 0.46 & 0.31 & & \\
\hline 98 & 125 & 92 & 60 & 78 & 38 & 50 & 40 & 7.28 & 7.16 & 0.15 & & & \\
\hline 106 & 121 & 98 & 60 & & & & & & & & & & \\
\hline 94 & 100 & 94 & 70 & 82 & 43 & 38 & 42 & 7.20 & 7.26 & 0.16 & & 0.20 & 0.16 \\
\hline 107 & 143 & 93 & 61 & 78 & 35 & 30 & 32 & 7.37 & 7.34 & 0.32 & 0.40 & 0.40 & \\
\hline 88 & 104 & 94 & 56 & 81 & 35 & 36 & 35 & 7.30 & 7.24 & 0.328 & 0.508 & & \\
\hline 16 & 24 & 2 & 7 & 10 & 4 & 6 & 5 & 0.08 & 0.08 & 0.12 & 0.16 & & \\
\hline \multicolumn{2}{|c|}{$<0.005$} & \multicolumn{2}{|c|}{$<0.001$} & \multicolumn{2}{|c|}{$<0.001$} & \multicolumn{2}{|c|}{$>0.05$} & \multicolumn{2}{|c|}{$<0.05$} & \multicolumn{2}{|c|}{$>0.05$} & & \\
\hline \multicolumn{14}{|c|}{ vascular resistance } \\
\hline $\begin{array}{l}122 \\
122\end{array}$ & 113 & $\begin{array}{l}95 \\
96\end{array}$ & $\begin{array}{l}31 \\
35\end{array}$ & $\begin{array}{l}85 \\
89\end{array}$ & 22 & $\begin{array}{l}32 \\
31\end{array}$ & 36 & $\begin{array}{l}7.37 \\
7.46\end{array}$ & 7.21 & $\begin{array}{l}1.00 \\
0.23\end{array}$ & 0.40 & 0.34 & \\
\hline 112 & 126 & 97 & 60 & & 35 & & 33 & & 7.37 & & & & \\
\hline 142 & 144 & 96 & 54 & & & & & & & & & & \\
\hline 70 & 62 & 93 & 65 & 81 & 39 & 38 & 39 & 7.25 & 7.24 & 0.14 & 0.21 & 0.20 & 0.17 \\
\hline $112 \S$ & 1118 & 95 & 49 & & & & & & & & & & \\
\hline 24 & 31 & 2 & 14 & & & & & & & & & & \\
\hline \multicolumn{2}{|c|}{$>0.05$} & \multicolumn{2}{|c|}{$<0.005$} & & & & & & & & & & \\
\hline 968 & $107 \S$ & 95 & 53 & 828 & 348 & $36 \S$ & 368 & 7.318 & 7.248 & $0.39 \S$ & 0.448 & & \\
\hline 24 & 25 & 2 & 12 & 5 & 7 & 7 & 5 & 0.06 & 0.06 & 0.28 & 0.17 & & \\
\hline \multicolumn{2}{|c|}{$<0.02$} & \multicolumn{2}{|c|}{$<0.001$} & \multicolumn{2}{|c|}{$<0.001$} & \multicolumn{2}{|c|}{$>0.05$} & \multicolumn{2}{|c|}{$<0.05$} & \multicolumn{2}{|c|}{$>0.05$} & & \\
\hline
\end{tabular}

sure, a fall in pulmonary arterial volume from 31 to $22 \mathrm{ml}(\mathrm{p}<0.001)$, and no change in the combined volumes of the pulmonary capillaries and veins (Table II). In two dogs, reaction halftimes for bicarbonate and lactic acid were obtained before and during serotonin administration, and inspection of these data revealed no change in half-times.

\section{Discussion}

In our anesthetized dogs, the breathing of 7 to $11 \%$ oxygen in nitrogen mixtures produced an elevation of pulmonary. arterial blood pressure with a slight rise in left atrial pressure. As demonstrated by others (14-16) with arterial oxygen saturations above $55 \%$, pulmonary blood flow tended to remain unchanged and thus pulmonary vascular resistance increased. In spontaneously breathing dogs, the mean rise of pulmonary vascular resistance ranged from 38 to $48 \%$ (14-16), whereas in the present series of dogs that were artificially ventilated it increased $60 \%$. In conscious trained dogs, breathing of 6 to $15 \%$ oxygen in nitrogen mixtures increased both pulmonary vascular resistance and pulmonary blood flow at any inspired mixture (17). A rise in pulmonary vascular resistance was also found in conscious humans breathing $12 \%$ oxygen in nitrogen. Pulmonary blood volume remained unchanged or was slightly decreased under these circumstances (18, 19). In the present dog experiments, pulmonary blood volume showed a slight but significant increase.

Not all of our dogs had increased pulmonary vascular resistance in response to hypoxia. However, in those in which the response to hypoxia was characterized by increased pulmonary vascular resistance, there was a redistribution of blood among the segments of the pulmonary circulation. In every experiment there was either a significant fall, considered as a drop of greater than $3 \mathrm{ml}$ from control, or no change in pulmo- 
TABLE II

Effect of serotonin on

\begin{tabular}{|c|c|c|c|c|c|c|c|c|c|c|}
\hline \multirow{2}{*}{$\begin{array}{c}\text { Experi- } \\
\text { ment } \\
\text { no. }\end{array}$} & \multirow[b]{2}{*}{ Dog } & \multirow[b]{2}{*}{ Weight } & \multicolumn{2}{|c|}{$\begin{array}{l}\text { Mean pulmonary } \\
\text { arterial pressure }\end{array}$} & \multirow{2}{*}{\multicolumn{2}{|c|}{$\begin{array}{l}\text { Mean left atrial } \\
\text { pressure }\end{array}$}} & \multirow{2}{*}{\multicolumn{2}{|c|}{$\begin{array}{c}\text { Pulmonary blood } \\
\text { flow }\end{array}$}} & \multirow{2}{*}{\multicolumn{2}{|c|}{$\begin{array}{l}\text { Pulmonary vascu- } \\
\text { lar resistance }\end{array}$}} \\
\hline & & & Control & Serotonin* & & & & & & \\
\hline & & $\mathrm{kg}$ & \multicolumn{2}{|c|}{$m m \mathrm{Hg}$} & \multicolumn{2}{|c|}{$m m \mathrm{Hg}$} & \multicolumn{2}{|c|}{$L / \min$} & \multicolumn{2}{|c|}{$m m ~ H g / L / \min$} \\
\hline $\begin{array}{l}1 \\
2 \\
3 \\
4 \\
5\end{array}$ & $\begin{array}{r}7 \\
8 \\
9 \\
10 \\
11\end{array}$ & $\begin{array}{l}17.7 \\
13.6 \\
12.7 \\
14.5 \\
15.4\end{array}$ & $\begin{array}{l}13 \\
31 \\
43.5 \\
27 \\
9.5\end{array}$ & $\begin{array}{l}19 \\
47 \\
78 \\
45 \\
22.5\end{array}$ & $\begin{array}{l}2.5 \\
3 \\
3 \\
6.5 \\
3\end{array}$ & $\begin{array}{l}5 \\
5 \\
7 \\
6.5 \\
5\end{array}$ & $\begin{array}{l}1.89 \\
1.48 \\
1.06 \\
1.10 \\
1.96\end{array}$ & $\begin{array}{l}1.32 \\
1.44 \\
1.08 \\
0.97 \\
2.09\end{array}$ & $\begin{array}{r}5.56 \\
18.92 \\
38.11 \\
18.63 \\
3.31\end{array}$ & $\begin{array}{r}10.61 \\
29.17 \\
65.74 \\
39.69 \\
8.37\end{array}$ \\
\hline $\begin{array}{l}\text { Mean } \\
\text { SD } \\
\text { p }\end{array}$ & & & $\begin{array}{r}24.8 \\
12.4 \\
<\end{array}$ & $\begin{array}{r}42.3 \\
21.2 \\
.005\end{array}$ & $\begin{array}{l}3.6 \\
1.5 \\
z\end{array}$ & $\begin{array}{l}5.7 \\
0.9 \\
.05\end{array}$ & $\begin{array}{r}1.50 \\
0.36 \\
>\end{array}$ & $\begin{array}{l}1.38 \\
0.31 \\
05\end{array}$ & $\begin{array}{r}16.91 \\
12.40\end{array}$ & $\begin{array}{l}30.71 \\
21.05 \\
02\end{array}$ \\
\hline
\end{tabular}

* In these and subsequent calculations in this Table, the left column indicates control values, and the right column indicates serotonin values.

nary arterial blood volume. From this, one may infer that there was active constriction of the greater part, if not the whole, of the pulmonary arterial tree since it is the larger vessels that contain most of the blood volume (20). If the distending pressure in the pulmonary arterial tree is increased as would be the case if only the arterioles or some vessels farther downstream constricted, the pulmonary arterial blood volume would increase passively as a function of compliance of this segment. Since intrapleural pressure does not change during hypoxia (1), the change in distending pressure can be taken as the change in mean pulmonary arterial pressure. The compliance of the various segments of the pulmonary circulation has not been measured in the dog but can be estimated by extrapolation from data obtained in rabbits (21) by correcting for the difference in body size. In this way, pulmonary arterial compliance of the dog can be taken as 0.9 $\mathrm{ml}$ per $\mathrm{mm} \mathrm{Hg}$ and pulmonary venous compliance as $1.7 \mathrm{ml}$ per $\mathrm{mm} \mathrm{Hg}$. This estimation of pulmonary arterial compliance agrees well with that measured from the time constant (21) of the pulmonary arterial pressure pulse in one of our dogs. During hypoxia, mean pulmonary arterial pressure for the whole series of dogs increased a mean of $11.5 \mathrm{~mm} \mathrm{Hg}$ with a range of 6.5 to $27 \mathrm{~mm} \mathrm{Hg}$. Passive distension of the pulmonary arterial tree would have caused an increase of $11.5 \mathrm{~mm} \mathrm{Hg} \times$ $0.9 \mathrm{ml}$ per $\mathrm{mm} \mathrm{Hg}=10.4 \mathrm{ml}$. Because the mean volume of the pulmonary artery did not increase, we postulate that active constriction must have occurred even though, on the average, pulmonary arterial blood volume remained unchanged dur- ing the hypoxic stimulus. The combined volumes of the pulmonary capillaries and veins showed a significant elevation accompanied by a slight rise in left atrial pressure. The pulmonary capillary blood volume was not measured separately in the present experiments, but Forster (22) published data from human subjects on the diffusing capacity for carbon monoxide, and these data suggest that capillary volume is unchanged over an alveolar oxygen tension range from 60 to $600 \mathrm{~mm} \mathrm{Hg}$. Thus, the increase of combined volumes in the present study might be entirely due to an increase in venous volume. If a pulmonary venous compliance of $1.7 \mathrm{ml}$ per $\mathrm{mm} \mathrm{Hg}$ and transmission to the pulmonary veins of the $1.5 \mathrm{~mm} \mathrm{Hg}$ increase in left atrial pressure are assumed, the passive increase of volume in the veins should be $2.6 \mathrm{ml}$. However, if it is assumed that the pulmonary capillary blood volume is constant during hypoxia, the venous volume increased $11 \mathrm{ml}$, and this suggests that active venous vasodilation might occur.

In the pulmonary circulation, the precapillary, capillary, and postcapillary regions, respectively, have been considered as major vasoactive sites. If the pulmonary and systemic vascular trees were comparable with respect to their reactive sites, the major resistance to flow should be at the pulmonary arteriolar level. However, structurally, the arterioles of the human and canine pulmonary circulations seem poorly equipped for intense vasoconstriction. Unlike systemic arterioles of comparable size, pulmonary arterioles contain scanty amounts of smooth muscle in their walls. Instead, larger quantities of smooth muscle are found in the walls of pulmonary arteries 100 to $1,000 \mu$ in 
TABLE II

pulmonary circulation

\begin{tabular}{|c|c|c|c|c|c|c|c|c|c|}
\hline \multirow{2}{*}{\multicolumn{2}{|c|}{$\begin{array}{c}\text { Pulmonary blood } \\
\text { volume }\end{array}$}} & \multirow{2}{*}{\multicolumn{2}{|c|}{$\begin{array}{l}\text { Pulmonary } \\
\text { arterial blood } \\
\text { volume }\end{array}$}} & \multirow{2}{*}{\multicolumn{2}{|c|}{$\begin{array}{l}\text { Pulmonary capillary } \\
\text { and venous } \\
\text { blood volume }\end{array}$}} & \multicolumn{4}{|c|}{ Reaction half-time } \\
\hline & & & & & & Bic & & $\mathrm{La}$ & \\
\hline \multicolumn{2}{|c|}{$m l$} & \multicolumn{2}{|c|}{$m l$} & \multicolumn{2}{|c|}{$m l$} & \multicolumn{4}{|c|}{ second } \\
\hline $\begin{array}{r}172 \\
151 \\
116 \\
79 \\
162\end{array}$ & $\begin{array}{r}150 \\
141 \\
108 \\
99 \\
132\end{array}$ & $\begin{array}{l}31 \\
46 \\
31 \\
25 \\
24\end{array}$ & $\begin{array}{l}22 \\
34 \\
17 \\
16 \\
19\end{array}$ & $\begin{array}{r}141 \\
105 \\
85 \\
55 \\
138\end{array}$ & $\begin{array}{r}128 \\
107 \\
91 \\
83 \\
113\end{array}$ & $\begin{array}{l}0.42 \\
0.43 \\
0.29\end{array}$ & $\begin{array}{l}0.46 \\
0.31\end{array}$ & $\begin{array}{l}0.68 \\
0.38 \\
0.25\end{array}$ & $\begin{array}{l}0.22 \\
0.26\end{array}$ \\
\hline $\begin{array}{r}136 \\
34\end{array}$ & $\begin{array}{r}126 \\
19\end{array}$ & $\begin{array}{r}31 \\
9\end{array}$ & $\begin{array}{r}22 \\
4 \\
05\end{array}$ & $\begin{array}{r}105 \\
32\end{array}$ & $\begin{array}{r}104 \\
18\end{array}$ & & & & \\
\hline
\end{tabular}

diameter (1). Even the pulmonary artery and its main branches are distinguished from the aorta both by their thinness and by their lesser mass of elastic elements and greater quantity of smooth muscle (23). Clearly, there is an anatomic basis for our deduction that the large pulmonary arteries constrict during hypoxia. Further, in vitro studies of main pulmonary arterial smooth muscle demonstrate its reactivity to vasoactive agents (23). Finally, there is angiographic evidence that medium- to large-size pulmonary arteries are capable of constriction during hypoxia. Hirschman and Boucek (24) showed that medium-sized pulmonary arteries in the dog constricted during hypoxia, but they did not study the main pulmonary artery. Aakhus and Johansen (25) carried out angiocardiography in unanesthetized ducks subjected to submersion asphyxia. These animals showed a rise in pulmonary arterial pressure during this maneuver and a reduction of the large pulmonary arteries to as little as half their control size during the diving experiments. The diameter reduction was most distinct in the central main pulmonary artery and was so striking that the paradoxical situation of a pulmonary artery with a smaller central than peripheral diameter often occurred. There were no accompanying changes in the diameters of the aorta or systemic arteries.

The mediation of pulmonary vasoconstriction during the breathing of low oxygen mixtures may differ from that during local alveolar hypoxia. In the latter, hypoxia vasoconstriction would serve as a protective mechanism to shunt blood to better ventilated parts of the lung. Regional arterial and arteriolar vasoconstriction might be a direct effect of the low oxygen tension in small airways and alveoli affecting the arteriolar or capillary vessel wall by diffusion (26) or as yet anatomically undemonstrated axon connections from the pulmonary veins to arteries (15).

Below an arterial oxygen saturation of $55 \%$, generally a large increase in pulmonary blood flow takes place and pulmonary vascular resistance falls. One way of looking at this is to say that the mechanism for vasoconstriction and shunting of blood to better ventilated parts of the lungs is discarded in favor of getting all possible oxygen to the tissues with the least burden on the right heart (14). In the present study, under these circumstances, the pulmonary arterial blood volume increased to an extent that could almost entirely be attributed to mechanical dilatation of the arterial tree by the increased pulmonary arterial blood pressure.

An alternative explanation is that the vasodilatation is part of the same spectrum of responses as the vasoconstrictive response. It is necessary to develop from the data in Table I, two relationships. These are $a$ ) the pressure-volume curve of the pulmonary arterial tree, and $b$ ) the relationship between change in the pulmonary arterial blood volume and pulmonary arterial conductance (conductance is the reciprocal of resistance).

Figure 1 shows data on individual dogs obtained during the control period, i.e., breathing air. This is a plot of pressure of the pulmonary arterial tree as the independent variable and volume of the pulmonary arterial tree as the dependent variable. A curve is established by assuming 


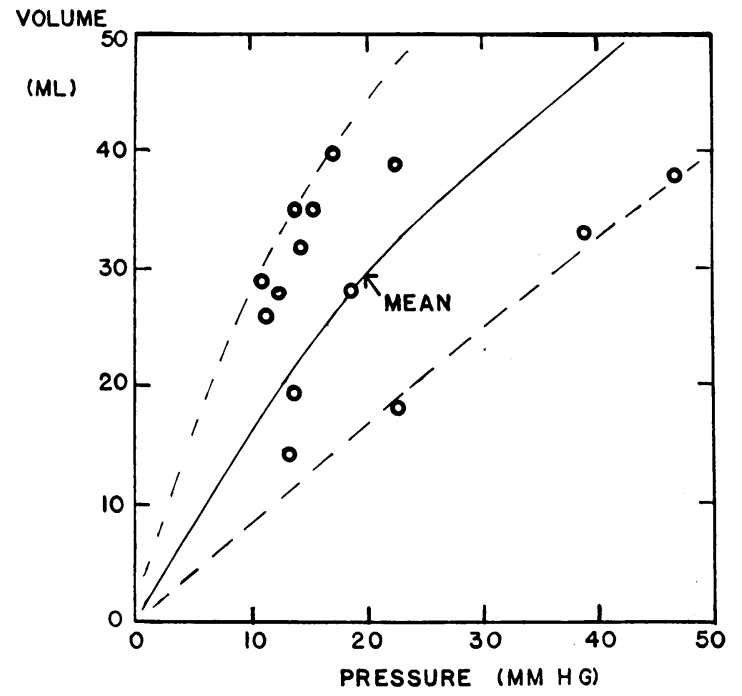

Fig. 1. Pressure-volume cUrve of the pUlmonary ARTERIAL TREE IN DOGS.

that $a$ ) when the pulmonary arterial pressure is zero, the volume of blood in the pulmonary artery is zero (the vessels would collapse if subjected to negative pressure) ; $b$ ) the dynamic compliance of the pulmonary arterial tree is taken to be $0.9 \mathrm{ml}$ per $\mathrm{mm} \mathrm{Hg}$ for reasons already presented above; and $c$ ) the distensibility of the small vessels is comparable to that of the large vessels (21). The dynamic compliance is drawn as a slope passing through the point of mean pressure and volume. A smooth curve (pressure-volume curve) is drawn through the origin of axes and mean pressure-volume point in such a way that the curve has the slope of dynamic compliance when passing through the latter point. Similar curves are drawn to enclose the extremes of observed control data.

Figure 2 shows the relationship of conductance of the entire pulmonary vascular bed to pulmonary arterial blood volume. The following assumptions are made in depicting this plot: 1) pulmonary arterial volume has a direct effect on pulmonary arterial conductance; 2) pulmonary arterial volume has no effect on pulmonary capillary and venous conductance; 3 ) initially, pulmonary arterial conductance equals the net pulmonary capillary and venous conductance $(27)$; 4) conductances add by reciprocals; 5) if pulmonary arterial volume becomes zero, the pulmonary vascular conductance becomes zero; and 6) if pulmonary arterial volume becomes infinitely large, the pulmonary vascular conductance would approach the limit imposed by the conductance of the pul-

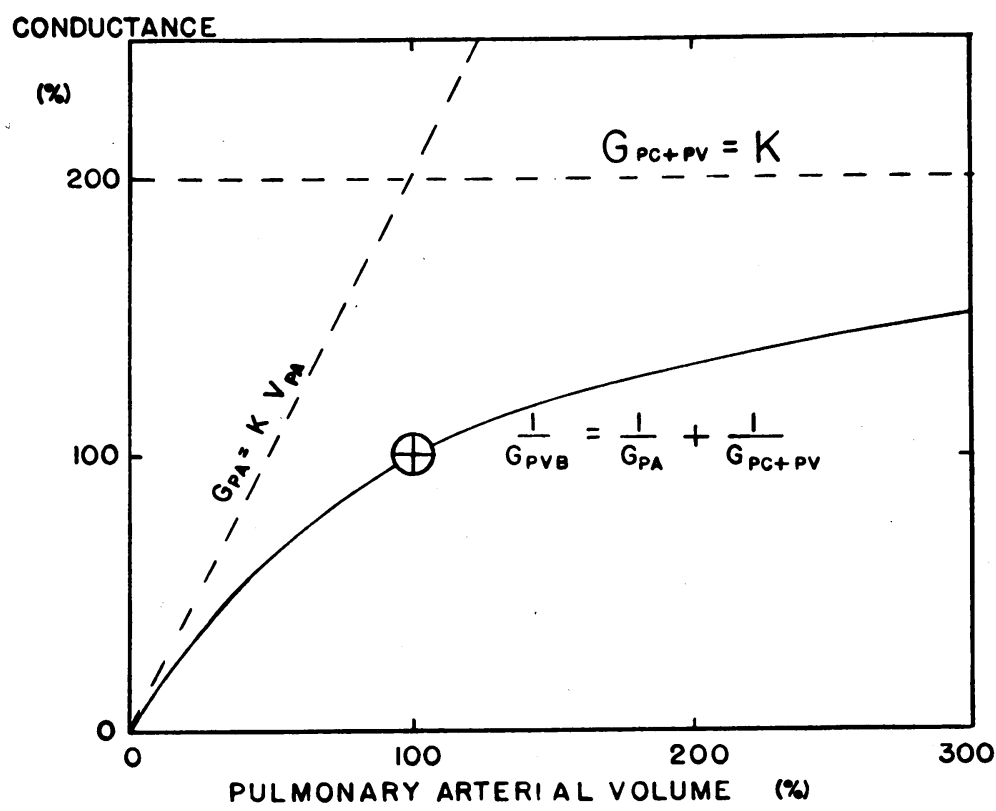

Fig. 2. Theoretical efFect of Changing pUlmonary ARTERIal bloOd volume UPON CONDUCTANCE OF THE PULMONARY VASCULAR BED. G= conductance, $\mathrm{V}=$ volume, $\mathrm{PA}=$ pulmonary artery, $\mathrm{PC}=$ pulmonary capillary, $\mathrm{PV}=$ pulmonary vein, and $\mathrm{PVB}=$ pulmonary vascular bed. 
monary capillaries and veins, which for practical purposes is taken as $200 \%$ of control conductance. We are now in a position to examine the theoretical sequence of events that occurs during hypoxia (Figure 3 ). The pulmonary arterial tone increases and pulmonary arterial volume is decreased. The decreased pulmonary arterial volume causes decreased total pulmonary conductance. The pulmonary blood flow would be diminished, except for circulatory responses, which seem to increase the pulmonary arterial pressure. The increased pulmonary arterial pressure causes increased pulmonary arterial volume. If pulmonary arterial volume were maintained or restored to normal, then pulmonary arterial conductance likewise would be maintained at approximately the control level. But if pressor compensation were too little, the pulmonary arterial volume and pulmonary arterial conductance would be subnor$\mathrm{mal}$; if pressor compensation were too great (overcompensation), then pulmonary arterial volume and conductance also might be larger than they were during the control period. However, whatever the degree of compensation, the tone would remain increased, as indicated by displacement of the pressure-volume curve to the right.

The actual data depicted in a pressure-volume plot and conductance-volume plot are depicted in
I. INITIAL RESPONSE: PULMONARY ARTERIAL CON-
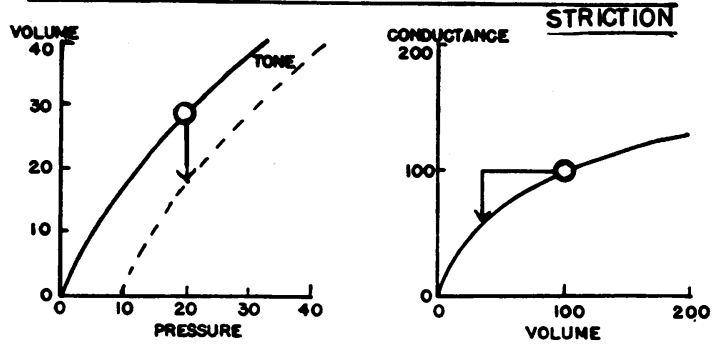

2. COMPENSATORY PULMONARY HYPERTENSION
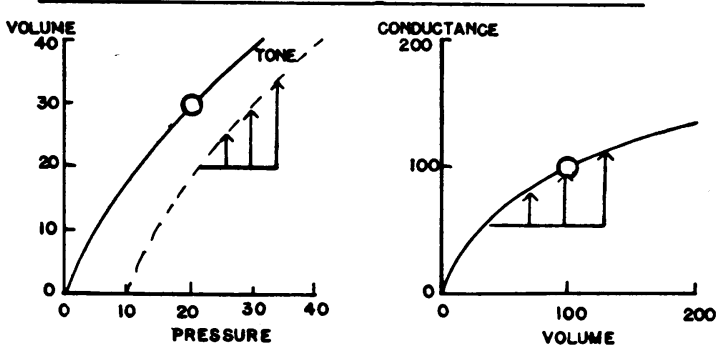

Fig. 3. Hypothetical SEQUENCE OF EVENTS DURING HYPOXIA OR SEROTONIN INFUSION.

Figures 4 and 5, respectively. In agreement with this theory, most points on the pressure-volume graph are displaced to the right, i.e., the tone is increased. The pulmonary arterial volume is below or above normal indicating different degrees of pressor compensation for the increased tone.

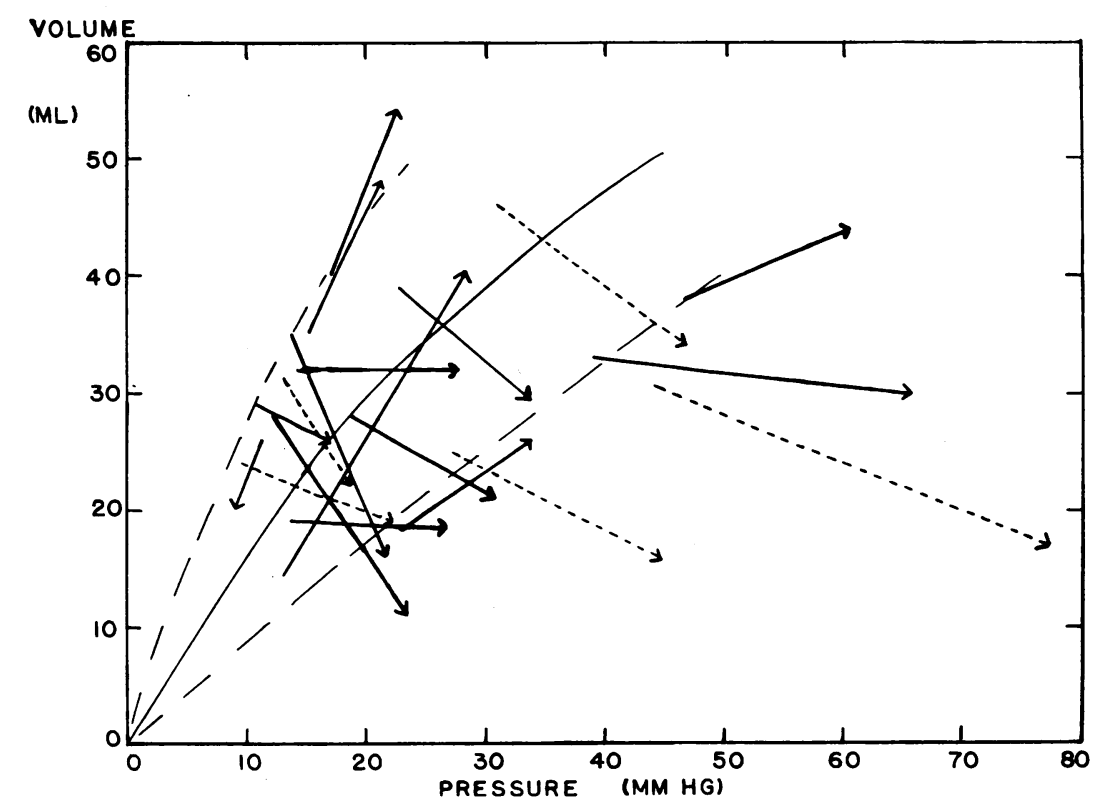

Fig. 4. Changes of PUlmonary ARTERIAL PRESSURE AND volume With hyPOXIA OR SEROTONIN. Hypoxia is indicated by the solid lines, and serotonin is indicated by the broken lines. 


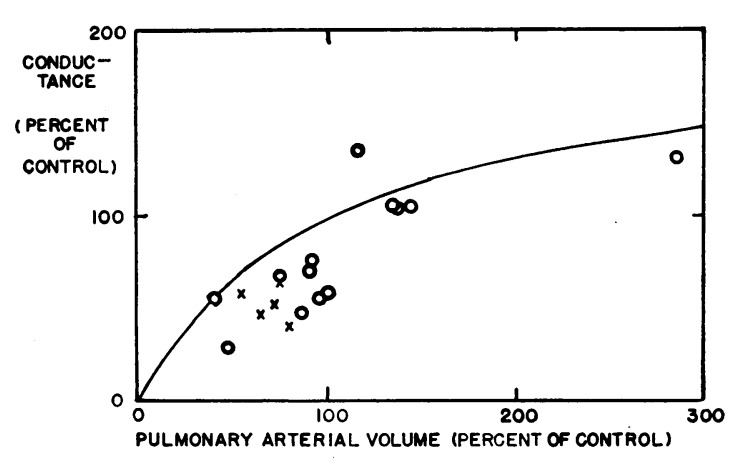

Fig. 5. EFFECT OF HYPOXIA OR SEROTONIN UPON PULMONARY VASCULAR CONDUCTANCE. Hypoxia is indicated by the circles, and serotonin is indicated by the crosses.

The conductance-volume points lie on or below the predicted curve.

If tonic pressure of the vessel walls increased equally throughout the pulmonary arterial tree, the lumen of the smaller vessels would decrease more than that of the larger vessels because the intraluminal inflating pressure inside the smaller vessels is less than it is inside the larger vessels; hence there would be less pressure opposing constriction of the walls. We suppose this is why most of the points plotted in Figure 5 lie slightly to the right of the theoretical conductance-volume curve. However, pulmonary arteriolar constriction alone, without concomitant constriction of the remainder of the pulmonary arterial tree, would be incompatible with our pressure-volume data (Figure 4), because the volume contributed by the pulmonary arterioles is so small compared to that of the remaining pulmonary arteries. Likewise, pulmonary capillary or venous constriction would not be compatible with our data for reasons already presented above.

The foregoing events account for the hypoxic changes in all the dogs on the basis of a continuous spectrum of response, thereby doing away with the need for separating the dogs into two groups on the basis of a rise or fall in pulmonary vascular resistance.

Serotonin, like hypoxia, also significantly constricted the large pulmonary arteries, as evidenced by the fall in pulmonary arterial volume (Figures 4, 5). A similar conclusion was reached by Bergel and Milnor (28) based upon studies of input impedance in the pulmonary artery of the dog. Previous investigators have shown that serotonin administered to dogs produces a slight increase of cardiac output, a marked rise of pulmonary arterial pressure and pressure in the small pulmonary veins, and little alteration of pressure in the large pulmonary veins or left atrium $(2,3,29)$. The effects on total pulmonary blood volume are related to the dose. In the dose employed by Shepherd, Donald, Linder, and Swan (2) and by us, no change in total pulmonary blood volume was demonstrated, whereas an increase in serotonin dose of some 15-fold, as used by McGaff and Milnor (29), produced a significant fall in pulmonary blood volume. Pulmonary capillary blood volume measured during a comparable dose given to our dogs rose $29 \%$ with a wide degree of scatter (30). This would suggest that venous volume fell in our studies since the combined blood volumes of the capillaries and veins did not change. It would confirm the notion that serotonin is a constrictor of the pulmonary veins. However, quantitatively, our measurements of pulmonary arterial blood volume indicate that serotonin is much more effective as a pulmonary arterial constrictor than as a pulmonary venous constrictor.

\section{Summary}

The measurements of pressure, flow, and volumes of the pulmonary circulation permit localization of the site of action of a vasoactive agent. In this study carried out in dogs, hypoxia or serotonin administration was investigated. During hypoxia, either a rise or fall in pulmonary vascular resistance may occur. The rise in pulmonary vascular resistance is associated with a significant decrease in pulmonary arterial blood volume, and, hence, constriction of the greater portion if not the entire pulmonary arterial tree must take place. There probably is concomitant venous vasodilation, which might be of an active nature. A fall in pulmonary vascular resistance during hypoxia was associated with passive dilatation of the pulmonary arterial tree. An analysis of the pressure-volume and the conductance-volume relationships of the pulmonary circulation indicates that pulmonary arterial vasoconstriction occurs in both types of responses. Serotonin produced pronounced arterial vasoconstriction and probably a lesser amount of venous constriction. These studies indicate that significant vasomotor activity is present throughout the pulmonary arterial tree, rather 
than confined to the arterioles as in the systemic circulation.

\section{References}

1. Fishman, A. P. Respiratory gases in the regulation of the pulmonary circulation. Physiol. Rev. 1961, 41, 214.

2. Shepherd, J. T., D. E. Donald, E. Linder, and H. J. C. Swan. Effect of small doses of 5-hydroxytryptamine (serotonin) on pulmonary circulation in the closed-chest dog. Amer. J. Physiol. 1959, 197, 963.

3. Aviado, D. M. Pulmonary venular responses to anoxia, 5-hydroxytryptamine and histamine. Amer. J. Physiol. 1960, 198, 1032.

4. Feisal, K. A., J. Soni, and A. B. DuBois. Pulmonary arterial circulation time, pulmonary arterial blood volume, and the ratio of gas to tissue volume in the lungs of dogs. J. clin. Invest. 1962, 41, 390.

5. Hamilton, W. F., J. W. Moore, J. M. Kinsman, and R. G. Spurling. Studies on the circulation. IV. Further analysis of the injection method, and of changes in hemodynamics under physiological and pathological conditions. Amer. J. Physiol. 1932, 99, 534

6. Soni, J., K. A. Feisal, and A. B. DuBois. The rate of intrapulmonary blood gas exchange in living animals. J. clin. Invest. 1963, 42, 16.

7. Polgar, G., and R. E. Forster. Measurement of oxygen tension in unstirred blood with a platinum electrode. J. appl. Physiol. 1960, 15, 706.

8. Severinghaus, J. W., and A. F. Bradley. Electrodes for blood $\mathrm{pO}_{2}$ and $\mathrm{pCO}_{2}$ determination. J. appl. Physiol. 1958, 13, 515.

9. Rahn, H., and W. O. Fenn. A Graphical Analysis of the Respiratory Gas Exchange; The $\mathrm{O}_{2}-\mathrm{CO}_{2}$ Diagram. Washington, American Physiologic Society, 1955, Chart VII.

10. Wood, E. H. Oximetry in Medical Physics, O. Glasser, Ed. Chicago, Year Book, 1950, vol. 2, p. 664.

11. Croxton, F. E. Elementary Statistics with Applications in Medicine and the Biological Sciences, New York, Dover, 1959, p. 240.

12. Adcock, J. L. Pulmonary arterial lesions in canine dirofilariasis. Amer. J. vet. Res. 1961, 22, 655.

13. Wallace, C. R., and W. F. Hamilton. Study of spontaneous congestive heart failure in the dog. Circulat. Res. 1962, 11, 301.

14. Lewis, B. M., and R. Gorlin. Effects of hypoxia on pulmonary circulation of the dog. Amer. J. Physiol. $1952,170,574$.
15. Stroud, R. C., and H. Rahn. Effect of $\mathrm{O}_{2}$ and $\mathrm{CO}_{2}$ tensions upon the resistance of pulmonary blood vessels. Amer. J. Physiol. 1953, 172, 211.

16. Stroud, R. C., and H. L. Conn, Jr. Pulmonary vascular effects of moderate and severe hypoxia in the dog. Amer. J. Physiol. 1954, 179, 119.

17. Thilenius, O. G., P. B. Hoffer, R. S. Fitzgerald, and J. F. Perkins, Jr. Response of pulmonary circulation of resting, unanesthetized dogs to acute hypoxia. Amer. J. Physiol. 1964, 206, 867.

18. Fritts, H. W., Jr., J. E. Odell, P. Harris, E. W. Braunwald, and A. P. Fishman. Effects of acute hypoxia on the volume of blood in the thorax. Circulation 1960, 22, 216.

19. Yu, P. N. Active changes in pulmonary blood volume. Med. Thorac. 1962, 19, 191.

20. Sackner, M. A., K. A. Feisal, and D. N. Karsch. Size of gas exchange vessels in the lung. J. clin. Invest. 1964, 43, 1847.

21. Engelberg, J., and A. B. DuBois. Mechanics of pulmonary circulation in isolated rabbit lungs. Amer. J. Physiol. 1959, 196, 401.

22. Forster, R. E. The effects of changes in the partial pressures of inspired gases on the ventilation of respiratory dead space and gas diffusion in the lungs in Man's Dependence on the Earthly Atmosphere, K. E. Schaeffer, Ed. New York, Macmillan, 1962, p. 262.

23. Somlyo, A. V., and A. P. Somlyo. Vasomotor function of smooth muscle in the main pulmonary artery. Amer. J. Physiol. 1964, 206, 1196.

24. Hirschman, J. C., and R. J. Boucek. Angiographic evidence of pulmonary vasomotion in the dog. Brit. Heart J. 1963, 25, 375.

25. Aakhus, T., and K. Johansen. Angiocardiography of the duck during submersion asphyxia. Acta physiol. scand. 1964, 62, 10.

26. Staub, N. C. Site of action of hypoxia on the pulmonary vasculature. Fed. Proc. 1963, 22, 453.

27. Agostoni, E., and J. Piiper. Capillary pressure and distribution of vascular resistance in isolated lung. Amer. J. Physiol. 1962, 202, 1033.

28. Bergel, D. H., and W. R. Milnor. Pulmonary vascular impedance in the dog. Circulat. Res. 1965, $16,401$.

29. McGaff, C. J., and W. R. Milnor. Effects of serotonin on pulmonary blood volume in the dog. Amer. J. Physiol. 1962, 202, 957.

30. Young, R. C., Jr., H. Nagano, T. R. Vaughan, Jr., and N. C. Staub. Pulmonary capillary blood volume in dog: effects of 5-hydroxytryptamine. J. appl. Physiol. 1963, 18, 264. 